\title{
The Indian family fights diabetes: Results from the second Diabetes Attitudes, Wishes and Needs (DAWN2) study
}

\author{
Sanjay Kalra, Mathew John ${ }^{1}$, Manash P Baruah ${ }^{2}$ \\ Department of Endocrinology, Bharti Hospital and B.R.I.D.E., Karnal, ${ }^{1}$ Providence Endocrine and Diabetes Specialty Centre, Trivandrum, \\ ${ }^{2}$ Excel Centre Hospitals, Guwahati, Assam, India
}

The recently conducted DAWN2 study assessed the views and perceptions of various stakeholders, in 17 countries, on issue related to diabetes care. In short, DAWN2 is a multinational, interdisciplinary and multi-stakeholder study conducted in the following 17 countries from four continents: Algeria, Canada, China, Denmark, France, Germany, India, Italy, Japan, Mexico, the Netherlands, Poland, Russian Federation, Spain, Turkey, the UK and the USA. ${ }^{[1-3]}$ These stakeholders included not only people with diabetes (PWD) and health care professionals (HCPs) but also family members of PWD (FM). ${ }^{[1-3]}$ The DAWN2 study reported that FM experience significant impairment in psychological well-being, distress related to diabetes and negative impact on their own life. ${ }^{[2]}$ A large number of FM feel frustrated as they do not know how best to help the PWD in their families and are worried about the risk of hypoglycemia in PWD. In spite of all these issues, the majority of FM are willing to increase their involvement in diabetes care and in helping PWD deal with their emotions related to diabetes. ${ }^{[2]}$

The Indian society has always enjoyed a strong family structure. Traditional teaching enjoins parents to take care of their children when they are young, and children are expected to look after aged parents as well. Although the age-old joint family structure is gradually giving way to

\begin{tabular}{|l|l|}
\hline \multicolumn{2}{|c|}{ Access this article online } \\
\hline Quick Response Code: & Website: \\
\hline & www.josh.net \\
\hline & \\
\hline
\end{tabular}

nuclear set-ups, kinship and family ties still remain strong in India. Indian HCPs score the third highest among all 17 DAWN2 countries in agreeing that the involvement of FM is a vital part of good diabetes care. ${ }^{[3]}$ The Indian data regarding these issues, therefore, needs to be analyzed further.

\section{THE SUPPORTIVE FACE}

DAWN2 has assessed the views of PWD about support available for self-management. ${ }^{[1]}$ The DAWN Family Support Scale has been used to assess support received from the person most involved in diabetes care. India rates the second best on this score, and ranks highest on the DAWN Support for Diabetes Self-Management Profile.

As part of the DAWN2 interviews, PWD in all countries have also been asked about how supportive various groups of people have been in helping them. The family as well as "other people in the community" are voted as being most supportive in India, while friends are the second most supportive in India, after China. People at work or school are the most supportive in China, followed by Algeria, with India coming in at the third place. The Indian health care team also takes the third place, after Turkey and Spain. Thus, India is the only country to figure in the top three ranks in terms of all stakeholders providing support to PWD.

\section{THE Distressed FACE}

While FM in all 17 surveyed countries report varying impact of diabetes on their health, India presents a unique picture. The Indian FM certainly experience a high rate of diabetes distress (38.9 [33.6-44.1] vs. An overall score

Corresponding Author: Dr. Mathew John, Providence Endocrine and Diabetes Specialty Centre, Trivandrum - 695011 , India.

E-mail: drmathewjohn@yahoo.com 
of 32.2) on the Problem Areas in Diabetes-5 Diabetes Family Member scale. In this regard, the Indian family scores better (less distressed) only than the Algerian and Turkish families. India takes one rank better when FM distress is measured on the DAWN Impact of Diabetes Profile Family Member scale: India scores 54.5 (51.8-57.2) against a global mean of 51.8.

The Indian FM report a deeper negative impact of diabetes in their family, on various aspects of their own life, as compared with the FM from other countries.

These aspects include leisure activities (India's rank \#17), work or studies (\#17), physical health (\#15), emotional well-being (\#15), financial situation (\#11) and relationship with family, friends and peers (\#11). The Indian FM rank $15^{\text {th }}$ when reporting (lack of) a positive impact on at least one dimension of their health. They reveal the $2^{\text {nd }}$ highest worries about the risk of hypoglycemia in their relatives with diabetes as well (79.0 [68.9-86.5] \%). It is obvious, therefore, that FM bear a heavy burden of, and pay a heavy price for, diabetes in India.

\section{The Cheerful FACE}

In spite of the significant diabetes-related distress that they face, Indian FM seem to be resilient. India scores best (least) on the chances of likely depression in FM as measured by the World Health Organization-5 (WHO-5) scale (8.0 [5.3-11.8] \% vs. an overall mean $11.4 \%)$. The Indian FM also rank third on the WHO-5 psychological well-being scale (63.7 [59.7-67.7]), just behind Mexico and Denmark. Only 5.9\% (3.3-10.3\%) of the FM in India rate their quality of life as being poor or very poor, giving the country the $7^{\text {th }}$ rank in DAWN2.

Relatively lesser Indian FM perceive a moderate to very large burden in helping the person they live with manage diabetes (18.9 [11.9-28.6] \%). This is good enough for a third place showing as well, after Mexico and the Russian Federation. Also, fewer Indian FM report a negative impact on their relationship with the person who has diabetes (20.3 [14.0-28.6] \%) (rank \#5).

\section{THE INVOLVED FACE}

This cheerful face of the Indian family translates into involvement as well. The best communication between PWD and their FM seems to be in India: 63.5\% (58.169.0\%) reply that the PWD informs them about his/her needs and asks for support. This compares favorably with the global average of $51.6 \%$.
The Indian FM also score highest on their willingness to be somewhat/much more involved in diabetes care (59.5 [48.9-69.3] \%) than their global counterparts.

The Indian FM are the second most willing, after Algerians, to show willingness to be somewhat/much more involved in helping PWD deal with their feelings about diabetes (57.5 [47.5-66.1] \% vs. an overall mean of $45.6 \%$ ).

\section{THE WeAker FACE}

Surprisingly, in spite of relatively better communication and willingness to improve their involvement in diabetes care, Indian FM tend not to participate in diabetes education activities. Only 18.1\% (12.1-26.2\%) (rank\#12) Indian FM do so and, of them, only 54.7\% (37.1-71.2\%) find them useful (rank \#17; the worst possible). However, Indian FM do rely upon other sources of education, information or support (only 6.8 [3.6-12.5] \% report not relying on such sources) (rank \#2).

\section{THE INDIAN FAMILY PARADOX}

The preceding discussion uncovers two seemingly paradoxical situations in Indian FM:

- A high level of diabetes-related distress and negative impact on life, but minimal likelihood of depression and well-maintained psychological health.

- A high level of involvement in caring for PWD, but lack of participation in educational activities.

The high level of distress is understandable, considering the affection that FM have for each other in India. It is perhaps a tribute to the Indian family structure and psyche that, in spite of their obvious distress, Indian FM are able to maintain their psychological health. Perhaps this is achieved by channeling thoughts into communication, and then into action or involvement.

The low level of participation in educational activities may simply be because of the lack of availability of such programmes, or because they are poorly designed. Poor quality may actually act as a deterrent for utilization of whatever resources are available in the future as well. It may be possible that Indian FM compensate for lack of such education by utilizing alternative sources of support, such as peers, friends and social media.

\section{IMPLICATIONS FOR DIABETES CARE}

The cohort of Indian FM appears to be a brave group: People who are willing to put aside their distress in order 
to help their loved ones deal with diabetes. To help them, however, India must put in place mechanisms to identify and manage diabetes-related distress not only in PWD but also in their FM. Addressing fears about hypoglycemia by providing safer therapy and empowering them with hypoglycemia management tools is a practical example of such a mechanism. Structured educational programmes should be started for FM and should be popularized among them. Robust quality control must be ensured. A positive lining is that Indian HCPs score the third highest among all 17 DAWN2 countries in agreeing that the involvement of FM is a vital part of good diabetes care.

\section{CONCLUSIONS}

India has a strong yet under-utilized, under-realized, soldier in the fight against diabetes. This soldier's commitment is unsurpassed. Hence, it is imperative to devise strategies to improve this soldier's efficiency. Programmes to reduce the psychological and emotional burden on FM, alleviate their worries and improve their access to good quality diabetes education will certainly help optimize the role of the FM in managing diabetes.

\section{REFERENCES}

1. Nicolucci A, Kovacs Burns K, Holt RI, Comaschi M, Hermanns N, Ishii $\mathrm{H}$, et al. Diabetes Attitudes, Wishes and Needs second study $\left(\mathrm{DAWN} 2^{\mathrm{TM}}{ }^{\text {): }}\right.$ Cross-national benchmarking of diabetes-related psychosocial outcomes for people with diabetes. Diabet Med 2013;30:767-77.

2. Kovacs Burns K, Nicolucci A, Holt RI, Willaing I, Hermanns N, Kalra S, et al. Diabetes Attitudes, Wishes and Needs second study (DAWN2 ${ }^{\mathrm{TM}}$ ): Cross-national benchmarking indicators for family members living with people with diabetes. Diabet Med 2013;30:778-88.

3. Holt RI, Nicolucci A, Kovacs Burns K, Escalante M, Forbes A, Hermanns N, et al. Diabetes Attitudes, Wishes and Needs second study (DAWN2 ${ }^{\mathrm{TM}}$ ): Cross-national comparisons on barriers and resources for optimal care-healthcare professional perspective. Diabet Med 2013;30:789-98.

How to cite this article: Kalra S, John M, Baruah MP. The Indian family fights diabetes: Results from the second Diabetes Attitudes, Wishes and Needs (DAWN2) study. J Soc Health Diabetes 2014;2:3-5.

Source of Support: Nil. Conflict of Interest: None declared. 